\title{
Acute haemodynamic effects of dobutamine in experimental sepsis-induced myocardial depression
}

\author{
DT Andreis ${ }^{1,2^{*}}$, W Khaliq $^{1}$, M Singer ${ }^{1}$ \\ From ESICM LIVES 2015 \\ Berlin, Germany. 3-7 October 2015
}

\section{Introduction}

Septic patients with myocardial depression are routinely treated with dobutamine [1]. Whether this strategy is desirable is questionable, as catecholamines increase cardiac work, reduce myocardial efficiency, and are cardiotoxic [2]. We can accurately predict mortality in a 72-hour fluid-resuscitated rat model of faecal peritonitis as early as 6 hours, based on the degree of myocardial depression (low stroke volume, high heart rate) [3]. This model offers a useful means of testing safety and efficacy of therapeutic interventions in predicted survivors and non-survivors.

\section{Objectives}

To compare dose-related haemodynamic effects of dobutamine at 6 hours post-insult in predicted survivors and non-survivors from faecal peritonitis.
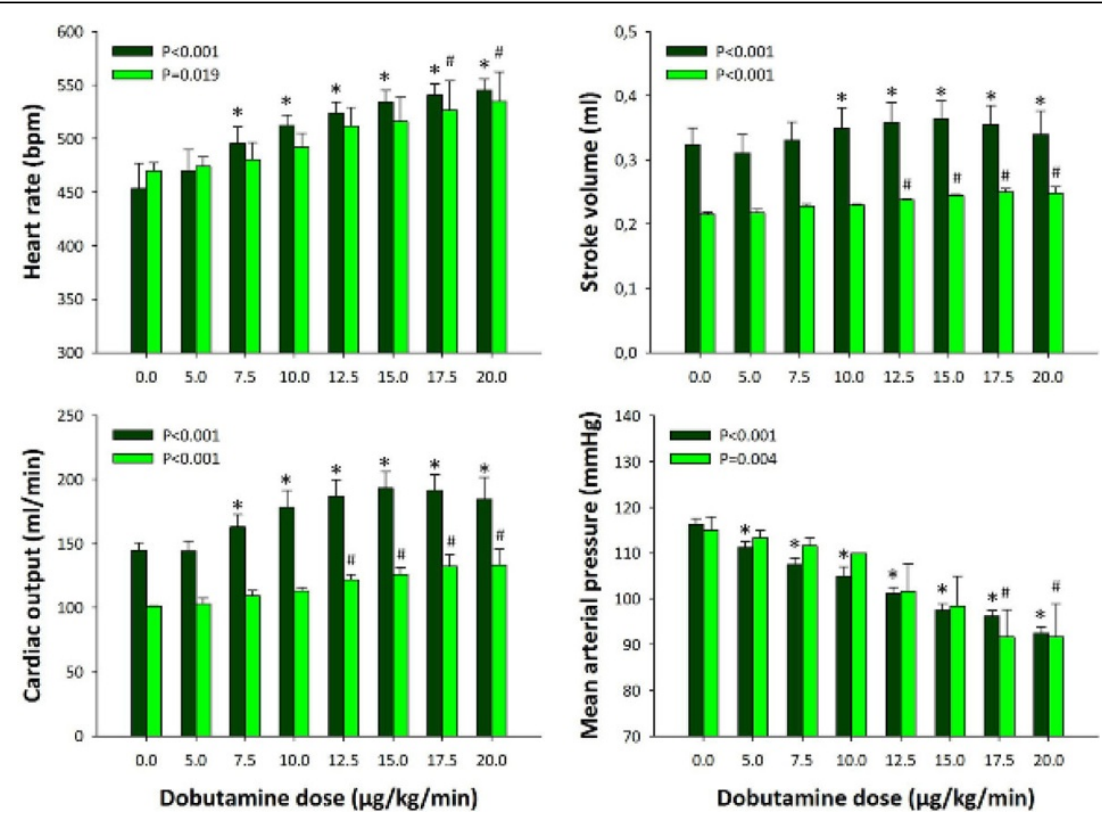

Figure $1 * p<0.05$ vs. baseline (good prognosis group, dark blue bars, $\mathrm{N}=4$ ). ${ }^{\#} \mathrm{p}<0.05$ vs. baseline (poor prognosis group, light blue bars, $\mathrm{N}=3$ ).

(c) 2015 Andreis et al.; This is an Open Access article distributed under the terms of the Creative Commons Attribution License (http:// creativecommons.org/licenses/by/4.0), which permits unrestricted use, distribution, and reproduction in any medium, provided the original work is properly cited. 


\section{Methods}

Male Wistar rats (341 $\pm 33 \mathrm{~g})$ were instrumented with arterial and central venous lines. Sepsis was induced (ip injection of faecal slurry), and fluid resuscitation $(10 \mathrm{ml} / \mathrm{kg} / \mathrm{h})$ started 2 hours later. At 6 hours, animals were assigned to good prognosis or poor prognosis groups - depending on echoderived stroke volume (cutoff value $0.20 \mathrm{ml}$, based on previous experiments). An additional fluid bolus $(10 \mathrm{ml} / \mathrm{kg})$ was given, followed by dobutamine infusion, increasing from 5 to $20 \mu \mathrm{g} / \mathrm{kg} / \mathrm{min}$ in $2.5-\mu \mathrm{g} / \mathrm{kg} / \mathrm{min}$ increments every 5 minutes, with haemodynamic measures recorded just prior. Repeated measures ANOVA and post-hoc Holm-Sidak test were used to seek statistically significant. differences.

\section{Results}

Stroke volume at $6 \mathrm{~h}$ was significantly lower in poor prognosis animals; good prognosis animals were more responsive than poor prognosis animals to dobutamine, with earlier rises in heart rate, stroke volume and cardiac output, and a fall in blood pressure (Figure 1).

\section{Conclusions}

The early hypodynamic circulatory profile of poor prognosis septic rats is associated with catecholaminehyporesponsiveness. This supports an underlying mechanism of impaired adrenergic signal transduction, and/or dysfunctional downstream pathways. Our data support the investigation of alternative agents for sepsis-induced myocardial depression.

\section{Grant Acknowledgement}

ESICM Basic Science Award, UK Intensive Care Society Young Investigator Award, NIHR.

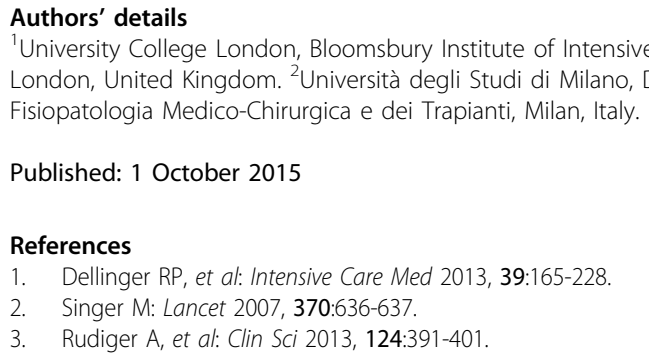
Fisiopatologia Medico-Chirurgica e dei Trapianti, Milan, Italy.

Published: 1 October 2015

\section{References}

1. Dellinger RP, et al: Intensive Care Med 2013, 39:165-228.

2. $\quad$ Singer M: Lancet 2007, 370:636-637.

3. Rudiger A, et al: Clin Sci 2013, 124:391-401.

'University College London, Bloomsbury Institute of Intensive Care Medicine, London, United Kingdom. ${ }^{2}$ Università degli Studi di Milano, Dipartimento di

doi:10.1186/2197-425X-3-S1-A799

Cite this article as: Andreis et al:: Acute haemodynamic effects of dobutamine in experimental sepsis-induced myocardial depression. Intensive Care Medicine Experimental 2015 3(Suppl 1):A799.

\section{Submit your manuscript to a SpringerOpen ${ }^{\mathcal{D}}$ journal and benefit from:}

- Convenient online submission

- Rigorous peer review

- Immediate publication on acceptance

- Open access: articles freely available online

- High visibility within the field

- Retaining the copyright to your article

Submit your next manuscript at $>$ springeropen.com 